\title{
Microscopic examination of Mesolithic serpent-like sculptured stones from southern Ukraine
}

\author{
Nadiia Kotova ${ }^{1}$, Dmytro Kiosak ${ }^{2, *}$, Simon Radchenko ${ }^{3}$ \\ $\&$ Larisa Spitsyna ${ }^{1}$
}

Two ophidian sculptured stones have been recovered from Mesolithic stratigraphic units at the site of Kamyana Mohyla 1 in southern Ukraine. Microscopic examination revealed traces of shaping and intentional ornamentation on the stones when compared to experimentally worked sandstones of similar quality. The finds broaden the distribution of movable rock art objects in the European Mesolithic.

Keywords: Ukraine, Kamyana Mohyla, Mesolithic, Kukrek, portable rock art

The open-air stratified site of Kamyana Mohyla I was discovered by V.M. Danilenko in the 1930s. It is situated in front of a natural sandstone mound (Kamyana Mohyla, Figure 1), where numerous engravings and figurines have been recovered, mostly dating to the Metal Ages (Mykhailov 2005). The site has been excavated by a joint Swiss-Ukrainian expedition since 2011. The excavation revealed a long sequence over $4.2 \mathrm{~m}$ deep, and the lower part comprises several Mesolithic habitations. The new finds described here come from this period, and consist of two zoomorphic sandstones, both intentionally shaped in order to resemble snake heads. They are a notable addition to the inventory of otherwise rare non-utilitarian objects of this age.

The 'older' figurine (Figure 2) was found in a Mesolithic cultural layer alongside an open fireplace, heaps of shells and occasional flint tools. The hearth provided two somewhat divergent radiocarbon dates: $8379 \pm 160$ and $7550 \pm 107 \mathrm{cal} \mathrm{BC}$, while the paucity of lithic finds precludes precise dating on the basis of material culture. The 'younger' figurine (Figure 3) came from another Mesolithic stratigraphic unit that contained a fireplace, which was radiocarbon-dated to $7424 \pm 46 \mathrm{cal} \mathrm{BC}$. The zoomorphic stone was accompanied by four bone points and a lithic assemblage that included some 'Kukrek inserts' and an obliquely

1 Institute of Archaeology of National Academy of Sciences of Ukraine, 12, Geroyiv Stalingrada Avenue, Kyiv 04210 , Ukraine

2 Odessa National I.I. Mechnikov University, 2 Dvorianska Street, Odessa 65082, Ukraine

3 Kyiv National University of Civil Engineering and Architecture, 31 Povitroflotskiy Avenue, Kyiv 03048, Ukraine

* Author for correspondence (Email: dkiosak@ukr.net)

(C) Antiquity Publications Ltd, 2018

ANTIQUITY 92 366, e2 (2018): 1-7

https://doi.org/10.15184/aqy.2018.249 


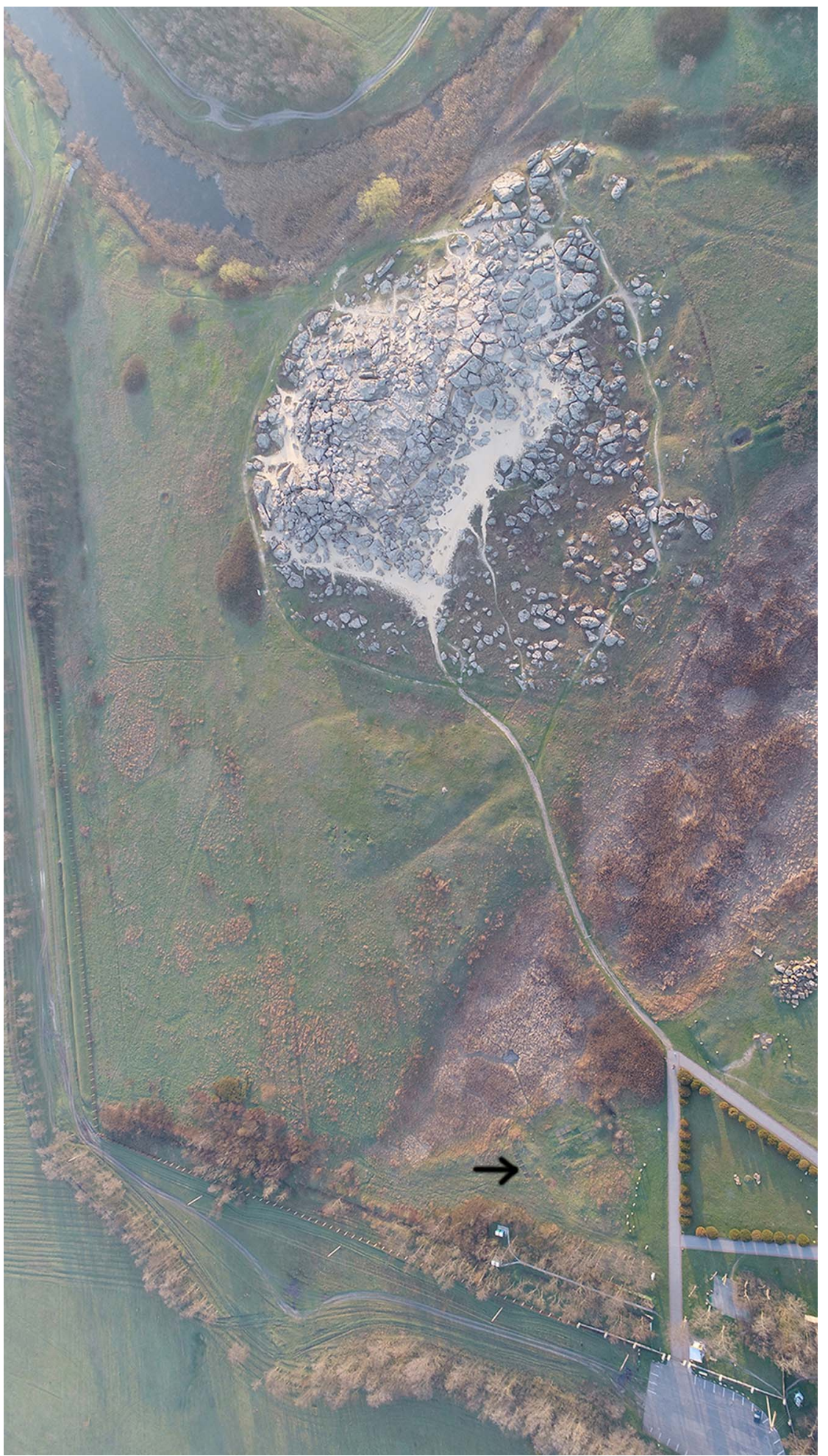

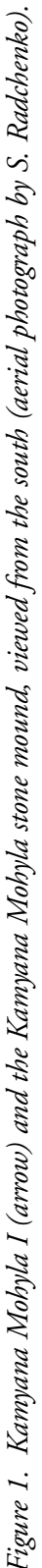

(C) Antiquity Publications Ltd, 2018 

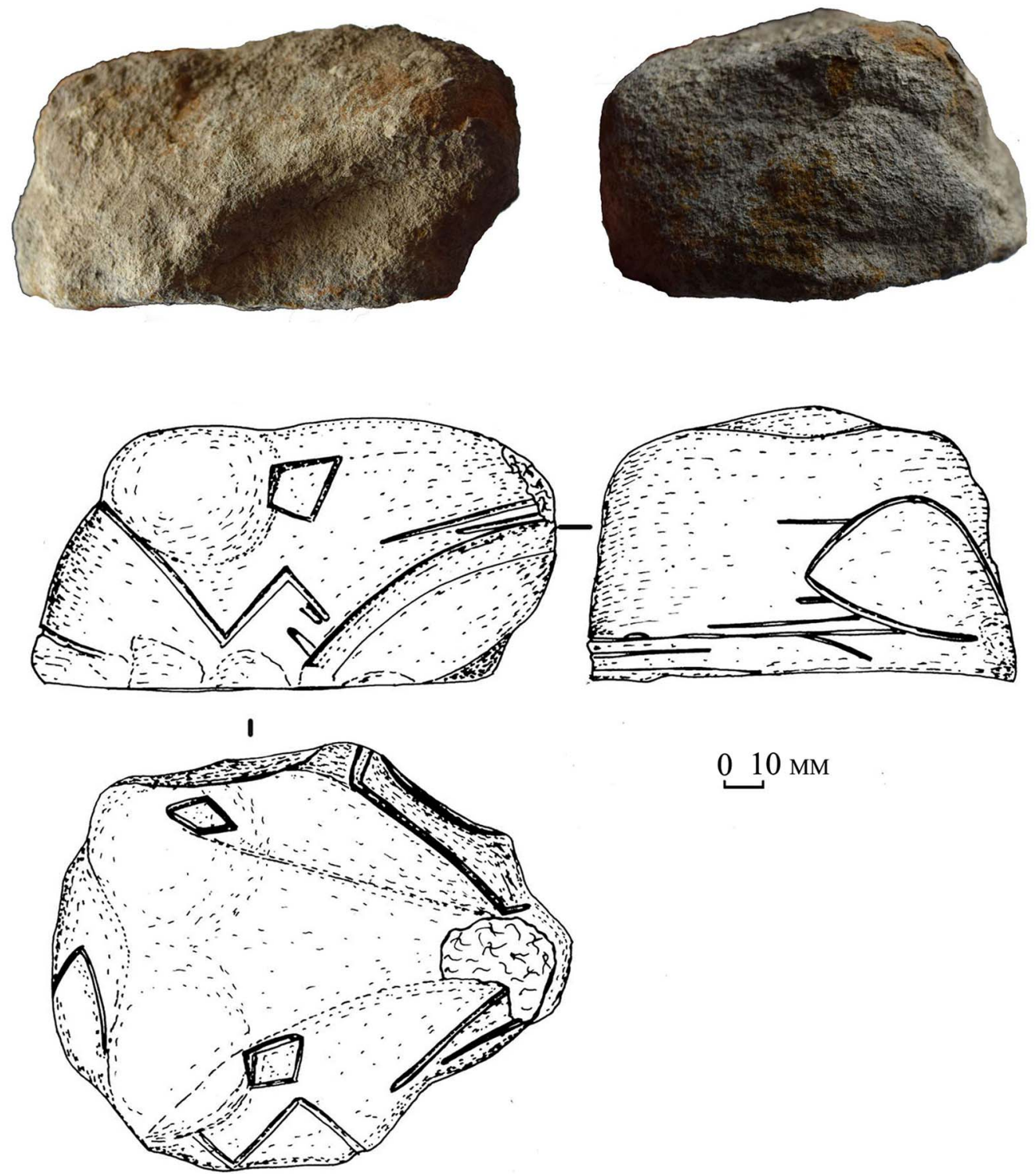

$0 \quad 10 \mathrm{MM}$

Figure 2. 'Older' figurine (figure by N. Kotova).

truncated bladelet (oblique point). These have close parallels with the local Mesolithic Kukrek technocomplex (Telegin 1982).

The figurines were examined under stereoscopic microscope (Optika SZM-45). Magnifying by a factor of 20 allows us to identify damage to single sandstone grains. These were compared to marks made by a flint tool on a sandstone block taken from the site. The 

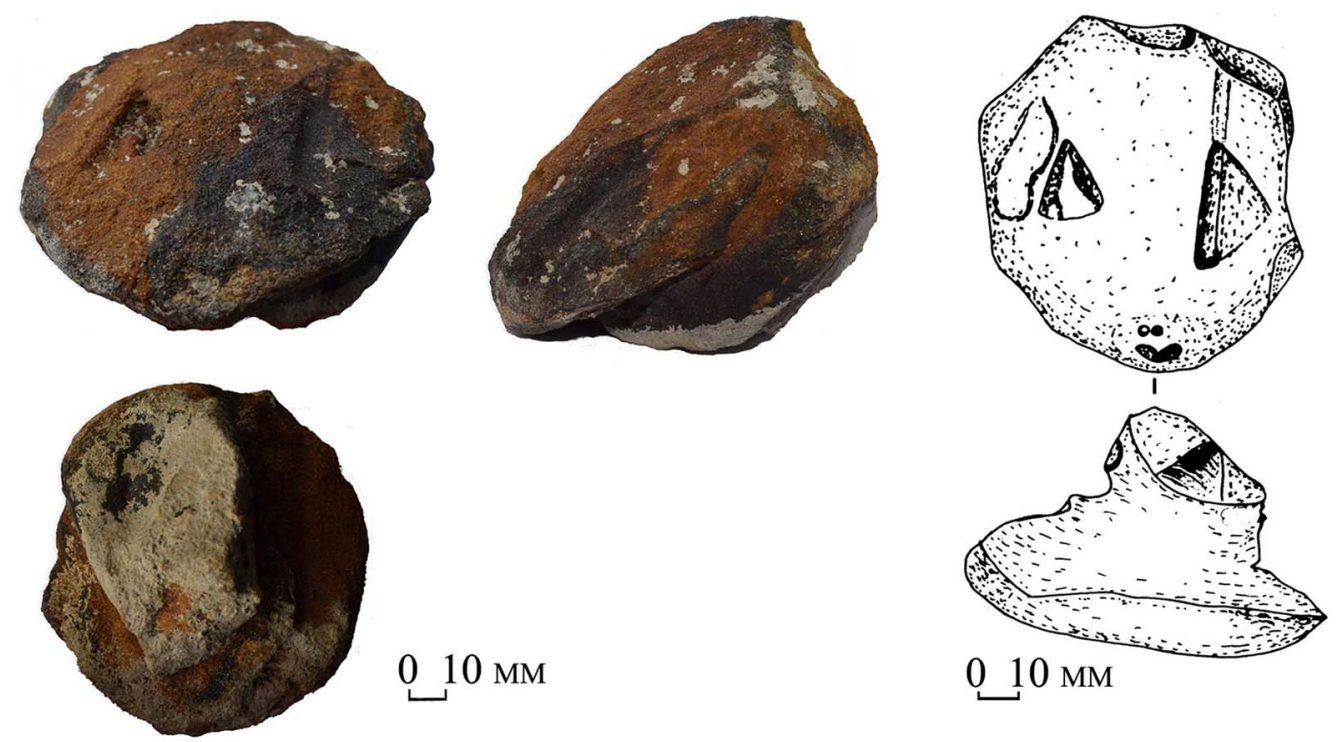

Figure 3. 'Younger' figurine (figure by N. Kotova).

examination reveals three ways of shaping the objects — striking, scratching and scraping (Figure 4). There are also some signs of water erosion on the younger figurine (Figure 5.1). Almost all of the surfaces received treatment, forming eyes, a 'neck', a mouse and some zig-zag patterns (Figures 4-5).

The older figurine measures $130 \times 68 \mathrm{~mm}$. The stone has a subtriangular shape with a flat lower part. Two rhombic eyes were carved on the upper surface alongside two knobs. A wide long line represents a mouth. Several narrow lines and depressions are carved around the mouth, along with a zig-zag line on the left side of the head, continuing on the rear side with a triangle. The stone was damaged on the 'nose' during excavation. The most recent stone sculpture has a flattened shape with a clear 'neck'. It measures $85 \times 58 \mathrm{~mm}$. Two triangular eyes, a mouth in the shape of a butterfly and two points as a nose were carved on it. The closest comparator for the new finds comes from Kamyana Mohyla itself, where a fishlike stone was found out of stratigraphic context (Figure 6). Zig-zags were incised on bone points coming from the sites of Sursky I and Kizlevy V, and both zig-zags and rhomboids are found on bracelets from the cemetery of Vasylivka II. All these sites are slightly later in date than the Middle Mesolithic layer at Kamyana Mohyla I, and are considered to relate to the pottery-bearing Surska culture (Kotova 2003).

Serpent-like motifs are well known in Stone Age art outside Ukraine. These are mostly realised in softer materials (wood and antler) rather than stone. Ophidian images are present on the antler and bone tools of the Scandinavian and Baltic Mesolithic (Mundkur 1983). 


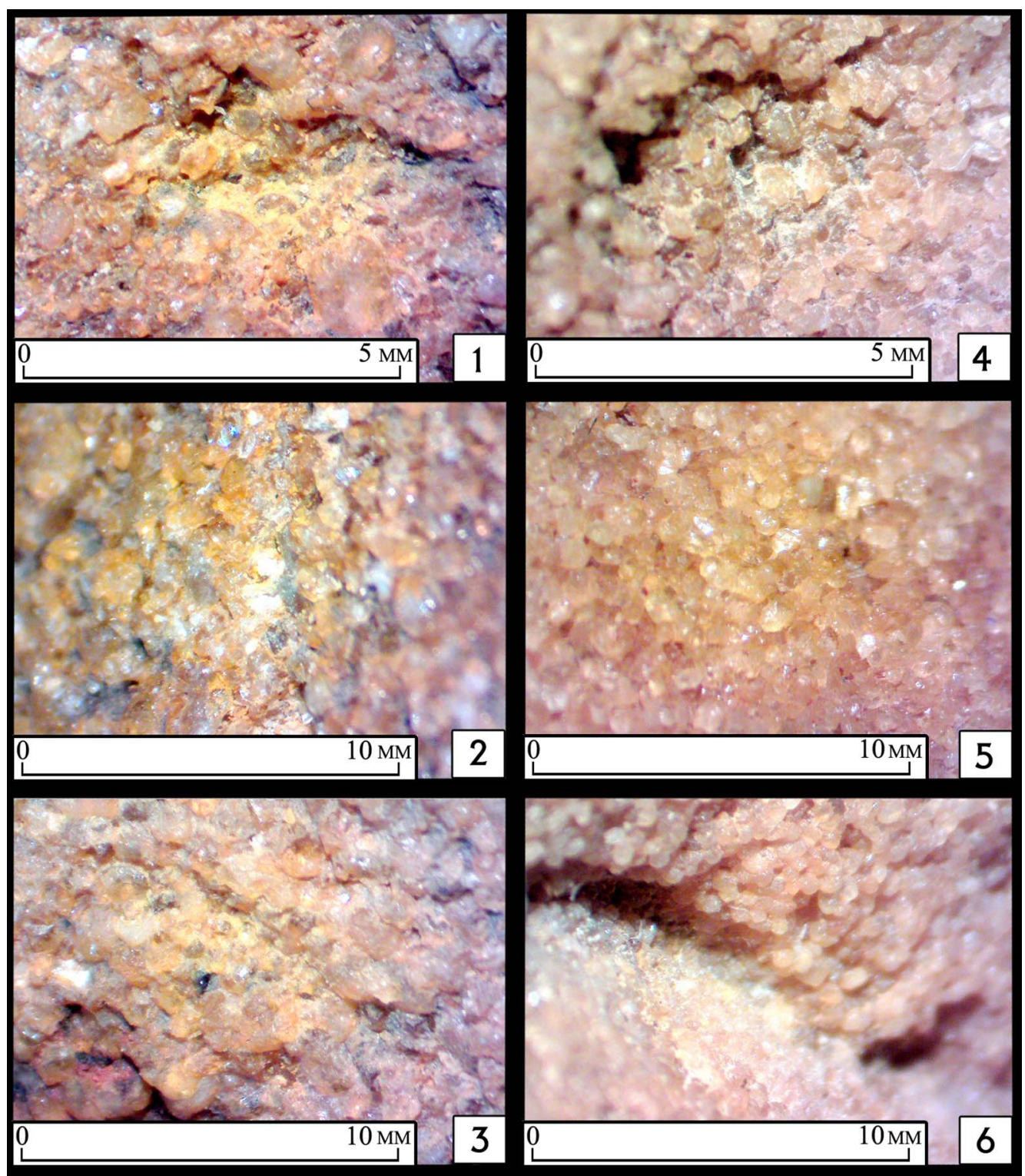

Figure 4. Microscopic examination of the 'older' figurine in comparison with experimental marks: 1-3) experimental marks; 4-6) traces on the figurine; 1 \&) strikes with the flint cutter; $2 \& 5$ ) scratches; $3 \& 6$ ) traces of scraping (figure by S. Radchenko).

Zig-zags were applied for the decoration of famous stone sculptures from Lepenski Vir (Srejović 1972), while zoomorphic stone figurines from the north Azov Sea region also provide parallels. Alternatively, the schematic realisation of images and decorative patterns on the Kamyana Mohyla examples connects them to another category of Mesolithic portable art- 


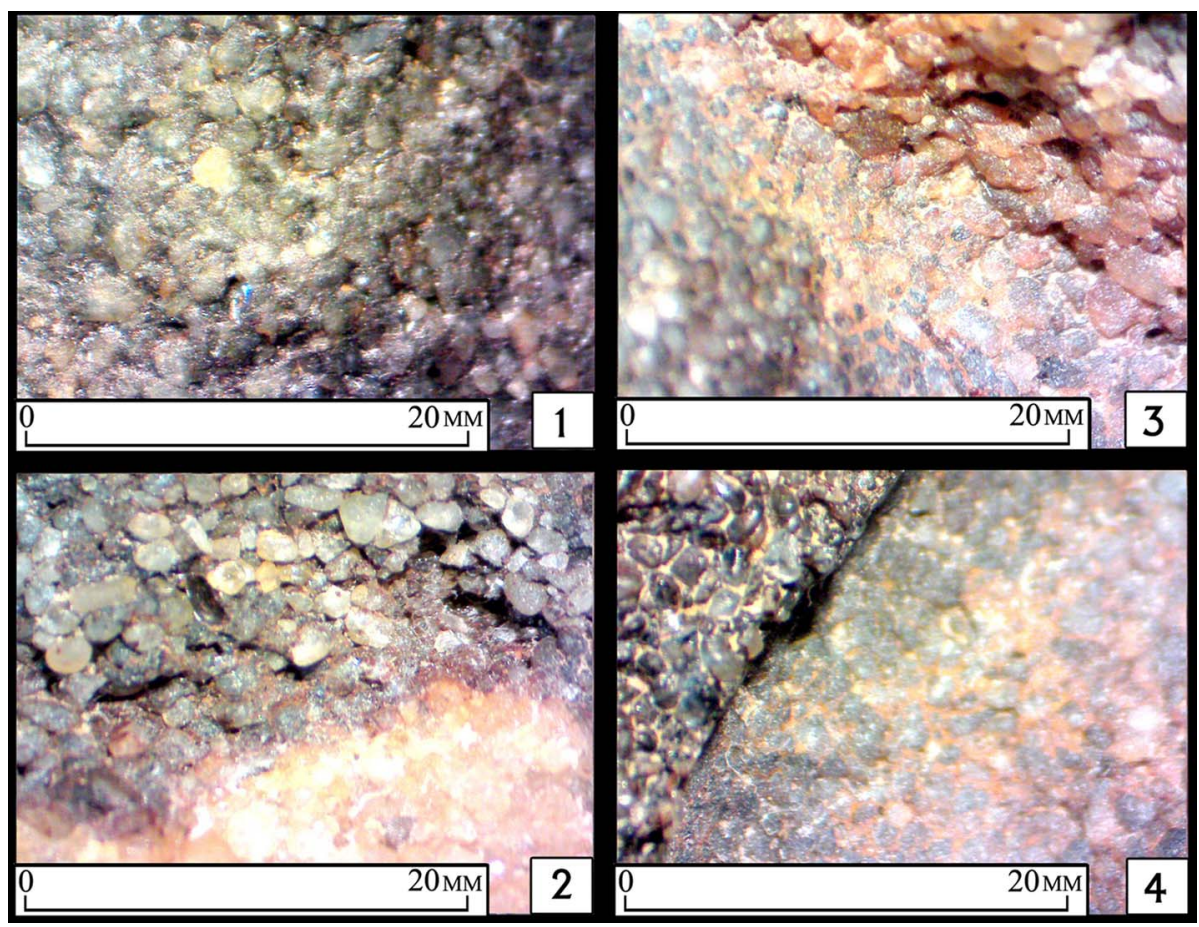

Figure 5. Microscopic examination of the 'younger' figurine: 1) traces of water erosion; 2) traces of scraping near the 'neck'; 3) traces of strikes on the nose; 4) traces of scraping on the left eye (figure by S. Radchenko).

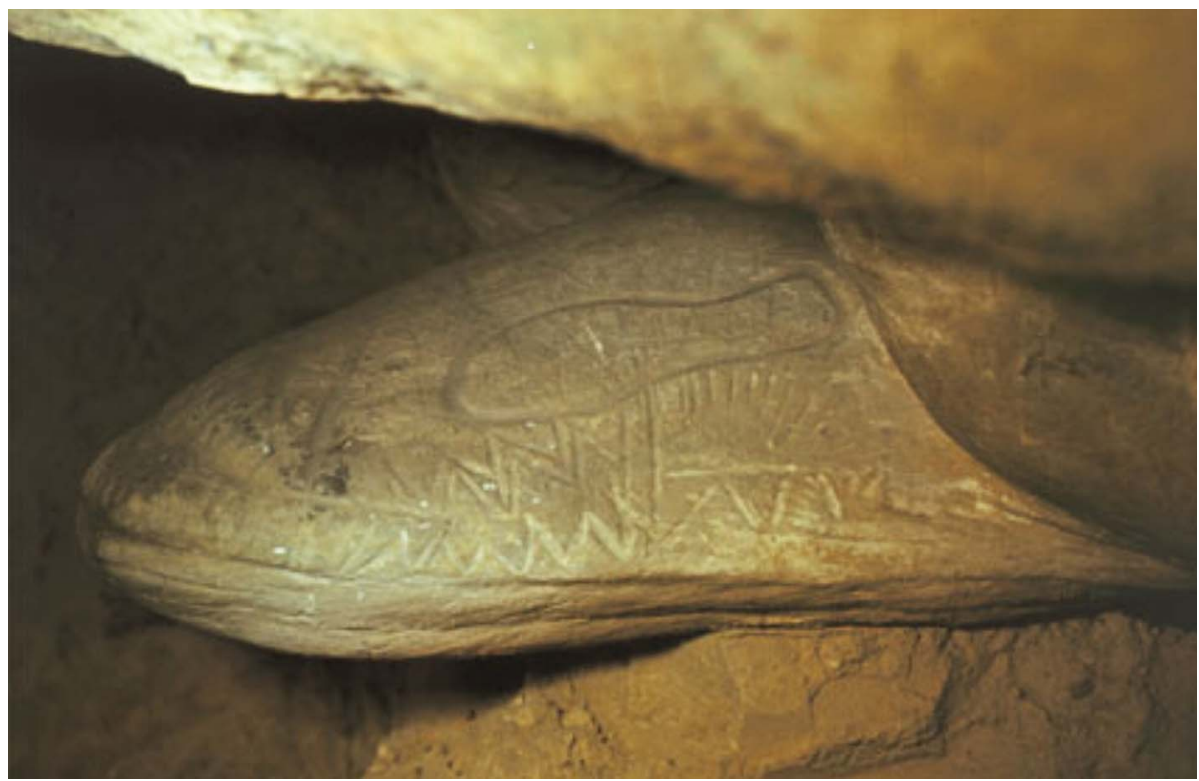

Figure 6. Fish-like stone from the Kamyana Mohyla mound (image courtesy of B. Mykhailov).

(C) Antiquity Publications Ltd, 2018 
pebble-tokens with incised ornaments. The latter are known from many Mesolithic contexts from Britain (Milner et al. 2016) up to the Ural Mountains (Zhilin 2015). The Kamyana Mohyla 'snakeheads' may represent a variety of these tokens, and thus a next step towards $3 \mathrm{D}$ sculptures, as the support was shaped into a certain zoomorphic (ophidian) image.

\section{Acknowledgements}

This work is dedicated to Larisa Spitsyna, who passed away in the summer of 2018. The fieldwork on Kamyana Mohyla I was supported by the SNF SCOPES grant (Project IZ73Z0_152732).

\section{References}

Kotova, N.S. 2003. Neolithization in Ukraine. Oxford: John \& Erica Hedges Ltd.

Milner, N. et al. 2016. A unique engraved shale pendant from the site of Star Carr: the oldest Mesolithic art in Britain. Internet Archaeology 40. https://doi.org/10.11141/ia.40.8

Mundkur, B. 1983. The cult of the serpent: an interdisciplinary survey of its manifestations and origins. Albany: State University of New York Press.

Mykhailov, B.D. 2005. Petroglyphs of Kamyana Mohyla. The semantics, chronology and interpretation. Kyiv: MAUP (in Ukrainian).
SREJOVIć, D. 1972. Europe's first monumental sculpture: new discoveries at Lepenski Vir. London: Thames \& Hudson.

Telegin, D.J. 1982. Mezolitychni pamyatky Ukrainy (IX-VII tys. do n.e.) [Mesolithic sites of Ukraine (IX-VII mill. BC)]. Kyiv: Naukova dumka (in Ukrainian).

Zhilin, M.G. 2015. Ivanovskoe 7arheologicheskij pamjatnik mnogokratnogo zaselenija v verhnem Povolzh'e [Ivanovskoye 7-an archaeological site of multiple occupation phases in the Upper Volga region]. Zamiatninskij sbornik 4: 162-79 (in Russian). 